\title{
Lipid signaling in plants
}

\author{
Xuemin Wang ${ }^{1 *}$ and Kent D. Chapman ${ }^{2 *}$ \\ 1 Department of Biology, University of Missouri-St Louis and Donald Danforth Plant Science Center, St. Louis, MO, USA \\ 2 Department of Biological Sciences, Center for Plant Lipid Research, University of North Texas, Denton, TX, USA \\ *Correspondence: swang@danforthcenter.org; chapman@unt.edu
}

Edited by:

Steven Huber, US Department of Agriculture-ARS, USA

Membrane lipids provide both the structural basis for cell membranes and a rich source of cellular mediators that regulate many aspects of plant development and environmental interactions. Over recent years, lipids as hormones and signaling messengers have gained increasing attention in the plant biology community. This volume collected 20 articles, including both primary research articles and several timely reviews on lipid signaling pathways, from active researchers addressing various fundamental questions in lipid signaling in plants (Ibrahim et al., 2011; Alford et al., 2012; Benning et al., 2012; Berkey et al., 2012; Dave and Graham, 2012; Dieck et al., 2012; Ge et al., 2012; Guo and Wang, 2012; Jung et al., 2012; Koo and Howe, 2012; LorencKukula et al., 2012; Maatta et al., 2012; Pleskot et al., 2012; Scherer et al., 2012; Stenzel et al., 2012; Strawn et al., 2012; Teaster et al., 2012; Wager and Browse, 2012; Xia et al., 2012; Arisz et al., 2013). One important question addressed is what lipids act as mediators in plants, and several classes of lipids and their related metabolites have been described, including phosphatidic acid, oxylipins, phosphoinositides, sphingolipids, free fatty acids, lysophospholipids, $\mathrm{N}$-acylethanolamines, oxidatively modified galactolipids, and others. In addition, advances in mass spectrometry-based analysis, which allow sensitive identification of lipids with structural information, have raised many new questions: How many lipids are there in plants? How do plant lipidomes change in response to growth, developmental, and stress cues? As a result, many lipid mediators remain to be identified, and this volume provides a current, baseline knowledge on lipid signaling molecules and their actions in plants.

Signaling lipids are produced and metabolized by a number of enzymes described in this volume, including phospholipase Ds, phospholipase As, acyl hydrolases, phytosphingosine kinases, diacylglcerol kinases, fatty acid amide hydrolases. Each enzyme class has multiple members, which contribute to the spatial and temporal production of lipid mediators, as well as to the influence of specific molecular species for selected actions. Additional molecular complexity is afforded by the fact that each class of lipid mediators may be produced by different enzymes. Different approaches, such as genetic ablation of specific genes, enzymatic kinetics, lipid profiling, or differential metabolic labeling, have been applied. Deciphering the complexity of lipid molecular signals and their metabolism has been a challenge.

Lipid signaling plays diverse roles in various cellular and physiological processes. The involvement of lipid mediators has been discussed here in plant responses to hormones (e.g., abscisic acid and auxin), abiotic stresses, plant-microbe interactions, and in plant growth and development. Some intriguing aspects of plant lipid mediators are also addressed, such as how lipids might play roles as long distance mobile signals in addition to their localized actions, contributing to processes such as flowering and defense against pathogens. One major challenge has been to elucidate mechanistically how lipid mediators carry out their functions. Recent advances in oxylipins, particularly metabolites in the jasmonate pathway, provide an excellent example of how some key players in the signaling cascade that have been identified and interact directly with target proteins to influence changes in gene transcription. At the same time, these articles on oxylipins emphasize the difficulty of assigning functions to lipid mediators when multiple metabolites within a pathway have biological actions (i.e., OPDA, jasmonate and jasmonyl-leu, and probably others). Identifying lipid-interacting proteins represents an exciting area for future research that will improve our understanding of how different signaling networks in plant cells are integrated. However, translating the milieu of lipid metabolite changes in cells into the mechanisms for regulation of physiological processes in plants will remain a formidable challenge in the coming years.

Elsewhere in the volume, the contribution of lipid head-group differences and their potential for selective actions are suggested. The potential roles of phosphoinositides in nuclear function and in the dynamics of membrane trafficking and cell expansion are discussed. In addition, head-group modifications and their metabolites, like the myo-inositol phosphates, appear to play a role in energy homeostasis in plants. Furthermore, biophysical studies have provided information on how PA and its phosphorylated product, diacylglycerol pyrophosphate, interact with proteins and/or cell membranes, suggesting a means for different cellular effects of these two metabolically related classes of signaling lipids.

The publication of this book would not have been possible without the efforts of many people. First and foremost are the authors who responded enthusiastically to the call to contribute to the special volume. And the essential critical comments from the many peer reviewers are gratefully acknowledged which provided valuable feedback to ensure the highest quality, and up-to-date information in the articles. 


\section{REFERENCES}

Alford, S. R., Rangarajan, P., Williams, P., and Gillaspy, G. E. (2012). Myoinositol oxygenase is required for responses to low energy conditions in Arabidopsis thaliana. Front. Plant Sci. 3:69. doi: 10.3389/fpls. 2012.00069

Arisz, S. A., van Wijk, R., Roels, W., Zhu, J.-K., Haring, M. A., and Munnik, T. (2013). Rapid phosphatidic acid accumulation in response to low temperature stress in Arabidopsis is generated through diacylglycerol kinase. Front. Plant Sci. 4:1. doi: 10.3389/fpls.2013. 00001

Benning, U. F., Tamot, B., Guelette, B. S., and Hoffmann-Benning, S. (2012). New aspects of Phloemmediated long-distance lipid signaling in plants. Front. Plant Sci. 3:53. doi: 10.3389/fpls.2012.00053

Berkey, R., Bendigeri, D., and Xiao, S. (2012). Sphingolipids and plant defense/disease: the "death" connection and beyond. Front. Plant Sci. 3:68. doi: 10.3389/fpls.2012.00068

Dave, A., and Graham, I. A. (2012). Oxylipin signaling: a distinct role for the Jasmonic acid precursor cis(+)-12-Oxo-Phytodienoic acid (cisOPDA). Front. Plant Sci. 3:42. doi: 10.3389/fpls.2012.00042

Dieck, C. B., Boss, W. F., and Perera, I. Y. (2012). A role for phosphoinositides in regulating plant nuclear functions. Front. Plant Sci. 3:50. doi: 10.3389/fpls.2012.00050
Ge, H., Chen, C., Jing, W., Zhang, Q., Wang, H, Wang, R., et al. (2012). The rice diacylglycerol kinase family: functional analysis using transient RNA interference. Front. Plant Sci. 3:60. doi: 10.3389/fpls.2012. 00060

Guo, L., and Wang, X. (2012). Crosstalk between phospholipase D and sphingosine kinase in plant stress signaling. Front. Plant Sci. 3:51. doi: 10.3389/fpls.2012.00051

Jung, J., Kumar, K., Lee, H. Y., Park, Y. I., Cho, H. T., Ryu, S. B., et al. (2012). Translocation of phospholipase A2 $\alpha$ to apoplasts is modulated by developmental stages and bacterial infection in Arabidopsis. Front. Plant Sci. 3:126. doi: 10.3389/fpls. 2012.00126

Ibrahim, A., Schütz, A. L., Galano, J. M., Herrfurth, C., Feussner, K. Durand, T., et al. (2011). The alphabet of galactolipids in Arabidopsis thaliana. Front. Plant Sci. 2:95. doi: 10.3389/fpls.2011

Koo, A. J., and Howe, G. A. (2012). Catabolism and deactivation of the lipid-derived hormone jasmonoylisoleucine. Front. Plant Sci. 3:19. doi: 10.3389/fpls.2012.00019

Lorenc-Kukula, K., Chaturvedi, R., Roth, M., Welti, R., and Shah, J. (2012). Biochemical and moleculargenetic characterization of SFD1's involvement in lipid metabolism and defense signaling. Front. Plant Sci. 3:26. doi: 10.3389/fpls.2012. 00026
Maatta, S., Scheu, B., Roth, M. R., Tamura, P., Li, M., Williams, T. D. et al. (2012). Levels of arabidopsis thaliana leaf phosphatidic acids, phosphatidylserines, and most trienoate-containing polar lipid molecular species increase during the dark period of the diurnal cycle. Front. Plant. Sci. 3:49. doi: 10.3389/ fpls.2012.00049

Pleskot, R., Pejchar, P., Bezvoda, R., Lichtscheidl, I. K., Wolters-Arts, M. Marc, J., et al. (2012). Turnover of phosphatidic acid through distinct signaling pathways affects multiple aspects of Pollen tube growth in tobacco. Front. Plant Sci. 3:54. doi 10.3389/fpls.2012.00054

Scherer, G. F. E., Labusch, C., and Effendi, Y. (2012). Phospholipases and the network of auxin signal transduction with ABP1 and TIR1 as two receptors: a comprehensive and provocative model. Front. Plant Sci. 3:56. doi: 10.3389/fpls. 2012.00056

Stenzel, I., Ischebeck, T., Quint, M., and Heilmann, I. (2012). Variable regions of PI4P 5-kinases direct $\operatorname{PtdIns}(4,5) \mathrm{P}_{2}$ toward alternative regulatory functions in tobacco pollen tubes. Front. Plant Sci. 2:114 doi: 10.3389/fpls.2011.00114

Strawn, L., Babb, A., Testerink, C., and Kooijman, E. E. (2012). The physical chemistry of the enigmatic phospholipid diacylglycerol pyrophosphate. Front. Plant Sci. 3:40. doi: 10.3389/fpls.2012.00040
Teaster, N. D., Keereetaweep, J., Kilaru, A., Wang, Y. S., Tang, Y., Tran, C. N., et al. (2012). Overexpression of fatty acid amide hydrolase induces early flowering in arabidopsis thaliana. Front. Plant Sci. 3:32. doi: 10.3389/ fpls.2012.00032

Wager, A., and Browse, J. (2012). Social network: JAZ protein interactions expand our knowledge of Jasmonate signaling. Front. Plant Sci. 3:41. doi: 10.3389/fpls.2012.00041

Xia, Y., Yu, K., Gao, Q. M., Wilson, E. V., Navarre, D., Kachroo, P., et al. (2012). Acyl CoA binding proteins are required for cuticle formation and plant responses to microbes. Front. Plant Sci. 3:224. doi: 10.3389/ fpls.2012.00224

Received: 28 May 2013; accepted: 05 June 2013; published online: 27 June 2013.

Citation: Wang $X$ and Chapman KD (2013) Lipid signaling in plants. Front. Plant Sci. 4:216. doi: 10.3389/fpls. 2013.00216

This article was submitted to Frontiers in Plant Physiology, a specialty of Frontiers in Plant Science.

Copyright () 2013 Wang and Chapman. This is an open-access article distributed under the terms of the Creative Commons Attribution License, which permits use, distribution and reproduction in other forums, provided the original authors and source are credited and subject to any copyright notices concerning any third-party graphics etc. 